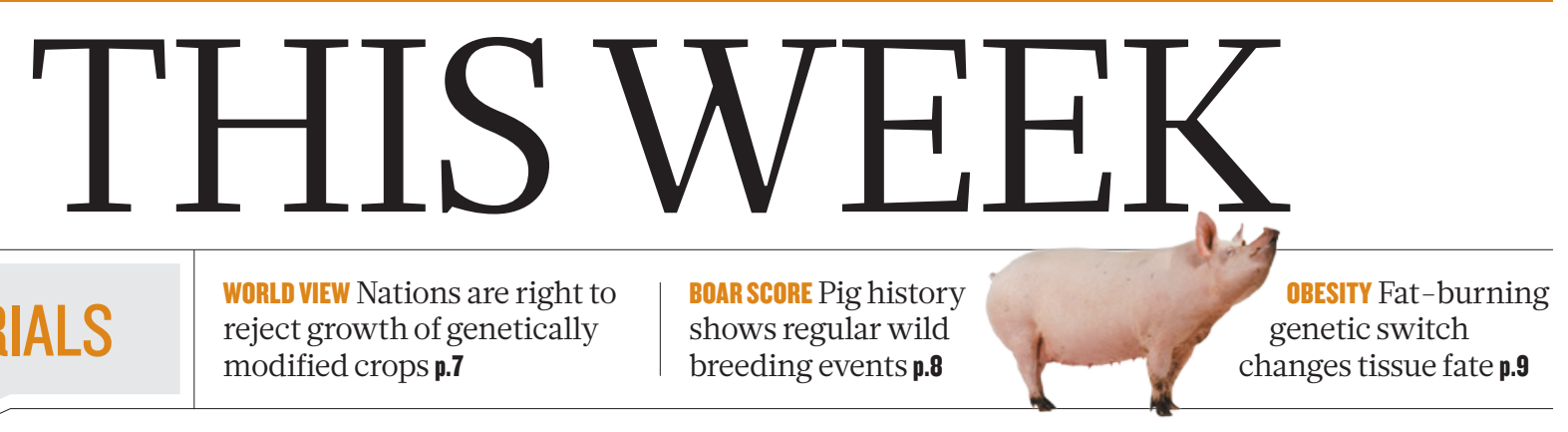

\title{
Personal responsibility
}

\section{The US Precision Medicine Initiative needs to tread carefully when revealing health and genetic data to participants.}

W hen Stephen Damiani's one-year-old son Massimo suddenly lost his ability to crawl and developed other problems in 2009, doctors could not diagnose him and told his parents that he was unlikely to live long. But Stephen, who is not a scientist, had his family's genomes sequenced and worked with geneticist Ryan Taft at the University of Queensland in Australia to identify a mutated gene.

Taft linked the gene to a class of neurodegenerative disorders involving the myelin sheath, which protects neurons. The discovery allowed Massimo to be treated with therapies for related conditions, and it helped a dozen or so other families worldwide who realized that their children had the same disorder.

Such commendable initiative and diligence is a testament to the power and promise of precision medicine - therapies targeted to individuals. But unlike rare conditions such as Massimo's, the overwhelming majority of genetic and environmental factors linked to common diseases contribute only slightly to disease risk. Hundreds of genes are probably involved in depression or breast cancer, for instance.

Researchers and ethicists have spent decades struggling with the question of how much data to release to patients. Many argue that revealing information about disease risk to individuals is unnecessary and irresponsible, owing to the potential for misinterpretation. Stoking people's fears in this way could lead to expensive, unwarranted and invasive medical tests. And such information could perpetuate the idea of genes as destiny - a low genetic risk for heart disease, for instance, could be used as an excuse to eschew a healthy diet or exercise. The darker side of the argument, which scientists hesitate to state publicly, is the worry that releasing data into the public sphere too soon could scupper their chances for publication.
Historically, most clinical trials have not returned individuals' information. But recent years have seen a move towards openness, from WikiLeaks to open-access publication. The attitude that a select few should control others' data is increasingly seen as paternalistic.

Treading this careful line between professional responsibility and transparency is the US Precision Medicine Initiative. Backed by President Barack Obama, who announced it in his January State of the Union address, the project aims to collect genetic, medical, physiological and environmental data from 1 million people and follow them for decades in an attempt to link these factors with health outcomes. Its planning committee, which is expected to propose a design for the project this month, seems to be undecided on the issue: the argument came up repeatedly and heatedly at a July committee workshop (see page 16).

The simplest but most restrictive approach is to inform people about findings only once they are discovered. Yet it seems incongruous to withhold health data when decisions such as organ donation are based on the idea that the body is the person's legal possession. A better solution would be withholding data by default, but releasing them if participants request it. Ideally, that release should occur only with guidance on how to interpret the information and alongside counselling on its significance.

Such a system would stretch the Precision Medicine Initiative's underwhelming US\$215-million budget, and could burden researchers who are searching for broader trends. Not every clinical study should be expected to take such an approach. But the initiative has tried to build its brand as an atypical, egalitarian study in which participants are partners with researchers. With proper cautions in place, access on request could demonstrate how to make good on that promise.

\section{Parched California}

\section{Drought highlights the state's lack of an ecological strategy.}

$\mathrm{F}$ or an unassuming little fish, the delta smelt (Hypomesus transpacificus) has received outsize attention. In the sprawling waterways of the Sacramento-San Joaquin river delta, which channel precious water throughout northern California, the smelt has served as an environmental sentry. When its numbers plummet, water managers flood the delta with fresh water, to the outrage of farmers who would rather have it nourishing their crops.

Yet the drought may finally do for the smelt. As California looks to enter its fifth year of drought, officials face difficult choices on how to manage water over the long term. So far, thanks to resilience built into the water system in past years, Californians are weathering the shortage remarkably well (see Amir AghaKouchak et al. Nature 524, 409-411; 2015). Cities have opted to control their love of lush lawns, and farmers have shifted to efficient irrigation and other water-saving measures.

But how long can the Golden State's lustre last? Two new reports (see go.nature.com/jpze97 and go.nature.com/okxrdo) highlight possible futures should the drought continue. And the outlook is not always that promising. Water managers cannot simply hope for a rainy winter, perhaps prompted by El Niño. Farmers will still pump groundwater for California's US\$46-billion agricultural industry, so water tables will continue to drop. More at risk are California's iconic ecosystems, from towering redwood trees to rivers teeming with salmon and trout. Wildlife managers have arranged to keep the most crucial wetlands damp for bird visits, and forestry managers extinguish wildfires as soon as they start. But such piecemeal approaches must be turned into a long-term strategy, much as farmers and urban planners have already done for their thirsty constituents.

Otherwise, the delta smelt may vanish for good. 